\title{
Pengelolaan Flight Information Region Di Wilayah Kepulauan Riau Dan Natuna
}

\author{
Mahfud Fahrazi \\ Fakultas Hukum Universitas Islam Kadiri \\ Jl. Sersan Suharmaji No.38 Kediri, Jawa Timur \\ mahfud@uniska-kediri.ac.id
}

Received: 23 September 2018; Accepted: 19 Juni 2018; Published: 22 Agustus 2019

DOI: 10.20885/iustum.vol26.iss2.art9

\begin{abstract}
This article focuses on the study of Flight Information Region (FIR) management in the Riau and Natuna Islands, which since 1946 is still controlled by Singapore. Although various attempts to take over the control have been carried out by the Indonesian government, it is yet to produce any meaningful results. The limitation of the problem in this study is first, the implications that arise from the management of FIR by Singapore on the Riau Islands and Natuna airspace. Second, the efforts that have been made by the Indonesian government to take over the management of FIR by Singapore over the Riau Islands and Natuna airspace. This research uses a normative legal research by analysing the legal issues through international treaties, legal regulations and other literature related to FIR management. The results of the study concluded first, the management of FIR by Singapore over the Riau Islands and Natuna influenced the enforcement of Indonesia's airspace sovereignty and national defence. Secondly, Indonesia's efforts and readiness to take over aviation navigation services include the formation of a special team from several ministries and other relevant institutions to prepare technical and operational steps as well as diplomatic steps in the framework of restructuring the FIR.
\end{abstract}

Keywords: Airspace; flight information region; sovereignty

\section{Abstrak}

Artikel ini memfokuskan kajian pada pengelolaan Flight Information Regional (FIR) di Kepulauan Riau dan Natuna yang sejak 1946 sampai saat ini masih dikendalikan oleh Singapura. Meskipun berbagai upaya untuk mengambil alih kontrol tersebut telah dilakukan oleh pemerintah Indonesia, tetapi belum membuahkan hasil. Batasan masalah dalam penelitian ini pertama, bagaimana implikasi yang timbul dari pengelolaan FIR oleh Singapura atas wilayah udara Kepulauan Riau dan Natuna? Kedua, upaya apa yang telah dilakukan oleh pemerintah Indonesia untuk mengambil alih pengelolaan FIR oleh Singapura atas wilayah udara Kepulauan Riau dan Natuna. Metode penelitian yang digunakan adalah penelitian hukum normatif dengan menganalisis masalah hukum melalui perjanjian internasional, perturan perundang-undangan, dan literatur lain yang terkait dengan pengelolaan FIR. Hasil penelitian menyimpulkan pertama, pengelolaan FIR oleh Singapura di atas Kepulauan Riau dan Natuna berpengaruh pada penegakan kedaulatan wilayah udara Indonesia serta pertahanan nasional. Kedua, upaya dan kesiapan Indonesia dalam mengambil alih layanan navigasi penerbangan di antaranya melalui pembentukan tim khusus dari beberapa kementerian dan lembaga terkait lainnya untuk menyiapkan langkah-langkah teknis dan operasional serta langkah-langkah diplomatik dalam rangka penataan kembali FIR.

Kata-kata Kunci: Ruang udara; flight information region; kedaulatan 


\section{Pendahuluan}

Kedaulatan merupakan bagian penting dari sebuah negara karena kedaulatan merupakan wujud eksistensi dari suatu negara. Kedaulatan dapat diartikan sebagai hak mutlak atau kekuasaan tertinggi yang dimiliki oleh suatu negara untuk melaksanakan fungsi, tugas, dan kewajiban di wilayahnya tanpa ada intervensi dari negara lain. Dalam konteks ilmu tata negara, I Wayan Parthiana menyatakan bahwa kedaulatan dapat diartikan sebagai kekuasaan yang tertinggi, mutlak, utuh, bulat dan tidak dapat dibagi-bagi, dan oleh karena itu tidak dapat ditempatkan di bawah kekuasaan lain. ${ }^{1}$ Lebih lanjut, Jean Bodin (1530-1596) menyatakan bahwa kedaulatan merupakan atribut dan ciri khusus dari suatu negara dan tanpa adanya kedaulatan, maka tidak akan ada yang dinamakan negara. ${ }^{2}$ Pikiran Jean Bodin yang dituangkan dalam tulisannya tersebut menunjukkan betapa pentingnya suatu kedaulatan bagi pelaksanaan pemerintahan dan sejak itu kedaulatan merupakan masalah sentral dalam pembahasan perangkat negara modern dan teori dari hukum internasional. ${ }^{3}$

Konsep kedaulatan dalam praktiknya di Indonesia tertuang jelas dalam Pasal 4 Undang-Undang Nomor 43 Tahun 2008 tentang Wilayah Negara (UU Wilayah Negara), yang menyatakan bahwa "Wilayah Negara meliputi wilayah darat, wilayah perairan, dasar laut, dan tanah di bawahnya serta ruang udara di atasnya, termasuk seluruh sumber kekayaan yang terkandung di dalamnya". ${ }^{4}$ Kemudian, pada Pasal 5 UU Wilayah Negara juga disebutkan bahwa batas wilayah negara di darat, perairan, dasar laut, dan tanah di bawahnya, serta ruang udara di atasnya ditetapkan atas dasar perjanjian bilateral dan/atau trilateral mengenai batas darat, batas laut, dan batas udara, serta berdasar pada peraturan perundang-undangan dan hukum internasional. ${ }^{5}$

Berkaitan dengan kedaulatan ruang udara, dalam dunia internasional telah disepakati melalui Pasal 1 Konvensi Chicago 1944 bahwa “Negara mempunyai

\footnotetext{
${ }^{1}$ Suryo Sakti Hadiwijoyo, Perbatasan Negara dalam Dimensi Hukum Internasional, Yogyakarta: Graha Ilmu, 2011, hlm. 8

2 Fred Isjwara, Pengantar Ilmu Politik, Bandung: Binacipta, 1996, hlm. 89

3 Eva Johan, "Pengaturan Mengenai Pesawat Udara Militer Menurut Hukum Udara Internasional", Perspektif, Vol. XV, No.3, 2010, hlm. 265

4 Pasal 4 Undang-Undang Nomor 43 Tahun 2008 tentang Wilayah Negara

${ }^{5}$ Pasal 4 dan 5 Undang-Undang Nomor 43 Tahun 2008 tentang Wilayah Negara
} 
kedaulatan yang bersifat lengkap dan eksklusif (penuh dan utuh) atas ruang udara di atas wilayahnya". ${ }^{6}$ Berdasarkan pasal tersebut diberikan pandangan bahwa perwujudan dari kedaulatan yang penuh dan utuh atas ruang udara di atas wilayah teritorial adalah a) setiap negara berhak mengelola dan mengendalikan secara penuh dan utuh ruang udara nasionalnya dan b) tidak ada satupun kegiatan atau usaha di ruang udara nasional tanpa mendapatkan izin terlebih dahulu atau sebagaimana telah diatur dalam suatu perjanjian udara antara suatu negara dengan negara lain, baik secara bilateral maupun multilateral.

Konvensi Chicago 1944 merupakan konstitusi dari organisasi penerbangan sipil internasional (the constitution of the ICAO) yang membentuk ketentuan hukum tentang transportasi udara internasional (international air transportation). Terdapat empat prinsip dalam Konvensi Chicago 1944, yaitu: pertama, kedaulataan (sovereignty), yang menyatakan bahwa negara-negara peserta Konvensi Chicago 1944 mengakui bahwa setiap negara di dunia rnemiliki kedaulatan penuh dan eksklusif atas ruang udara yang berada di atas wilayah kekuasaannya.

Kedua, wilayah (territory), yang menyatakan bahwa untuk keperluan Konvensi Chicago 1944, wilayah kekuasaan suatu negara adalah wilayah daratan dan lautan yang berbatasan dengannya yang berada di bawah kedaulatan, perlindungan, atau mandat dari negara tersebut.

Ketiga, pesawat sipil dan pemerintah (civil and state aircraft). Dalam hal ini, terbagi menjadi empat poin, yaitu: a) Konvensi Chicago 1944 banyak berlaku bagi pesawat terbang sipil dan tidak berlaku bagi pesawat terbang milik pemerintah suatu negara; b) pesawat yang digunakan untuk keperluan militer, pabean, dan layanan kepolisian dianggap sebagai pesawat terbang milik pemerintah; c) tidak ada pesawat terbang milik Pemerintah suatu negara yang boleh melewati wilayah udara negara lain atau mendarat di negara tersebut tanpa izin melalui perjanjian khusus, atau sebaliknya, dan dilaksanakan sesuai prosedur yang diperjanjikan; d) negara-negara peserta berusaha ketika membuat peraturan mengenai penerbangan sipil untuk membuat peraturan yang mengutakan keselamatan navigasi dari penerbangan sipil.

${ }^{6}$ Pasal 1 Konvensi Chicago 1944 
Keempat, penyalahgunaan penerbangan sipil (misuse of civil aviation), yang menyatakan bahwa negara-negara peserta setuju untuk tidak menggunakan penerbangan sipil untuk tujuan lain yang tidak sesuai dengan yang terjadi dalam Konvensi Chicago $1944 .^{7}$

Kolossov juga mengemukakan tentang prinsip hukum udara internasional, di antaranya: pengakuan kedaulatan penuh dan eksklusif dari setiap negara atas ruang udara di atas wilayahnya; kerjasama negara-negara dengan tujuan untuk memajukan atau mengamankan penerbangan dalam navigasi udara internasional, dan tatanan navigasi penerbangan di Indonesia yang memuat ruang udara yang dilayani, klasifikasi ruang udara, jalur penerbangan, dan jenis pelayanan navigasi penerbangan. ${ }^{8}$ Komitmen pemerintah Indonesia untuk memertahankan kedaulatan di ruang udara telah diwujudkan melalui pembentukan Pasal 5 Undang-Undang Nomor 1 Tahun 2009 tentang Penerbangan (UU Penerbangan), yang menyatakan bahwa "Negara Indonesia bardaulat penuh dan utuh atas wilayah udara Republik Indonesia".

Istilah Flight Information Region (FIR) dan Upper Flight Information Region (UIR) dikenal dalam dunia penerbangan. FIR dan UIR merupakan wilayah yang penetapannya tidak berdasarkan wilayah teritorial, tetapi ditetapkan berdasarkan kepentingan dan pertimbangan keselamatan penerbangan (safety consideration). ${ }^{9}$

Setiap pesawat udara yang melakukan penerbangan dalam lalu lintas udara harus diawasi. Tujuan antara lain untuk mencegah tabrakan antar-pesawat udara dan antara pesawat udara dengan halangan (obstacle) di daerah manuver (manouvering area), memperlancar dan menjaga keteraturan arus lalu lintas penerbangan, memberikan petunjuk dan informasi yang berguna bagi keselamatan dan efisiensi penerbangan, dan memberikan notifikasi kepada organisasi yang terkait untuk bantuan pencarian dan pertolongan. ${ }^{10}$

${ }^{7} \mathrm{Ni}$ Putu Anggraeni, "Convention on International Civil Aviation”, Indonesian Journal of International Law, Vol. 6, No. 4, 2009, hlm. 565-566

${ }^{8}$ I. H. Ph. Diederiks-Verschoor, Beberapa Persamaan Dan Perbedaan Antara Hukum Udara dan Hukum Ruang Angkasa Khusus Dalam Bidang Hukum Perdata Internasional, diterjemahkan oleh Bambang Iriani, Sinar Grafika, Jakarta, 1991, hlm. 10

9 Harry Purwanto ," Rute Penerbangan di atas Alur Kepulanan Perspektif Indonesia", Perspektif Hukum, http://perpus.hangtuah.ac.id/ojs/index.php/perspektif/article/view/28/25 diakses pada 25 Januari 2017

${ }_{10}$ Pasal 278 Undang-Undang Nomor 1 tahun 2009 tentang Penerbangan 
Pengendalian lalu lintas udara untuk wilayah ruang udara di Indonesia dibagi pada dua wilayah FIR, yakni FIR Jakarta dan FIR Makassar, yang dibantu FIR Singapura untuk wilayah di atas Batam, Matak, dan Natuna (sektor A, B, dan C). Untuk sektor A, Indonesia mendelegasikan tanggung jawab pelayanan navigasi dari permukaan laut hingga ketinggian 37 ribu kaki. Di sektor B, pendelegasian meliputi pemukaan laut hingga ketinggian tak terbatas. Sedangkan sektor C ditetapkan sebagai wilayah abu-abu (tidak termasuk dalam perjanjian karena masih terkait persoalan perbatasan dengan Malaysia). Di sektor A, FIR Singapura mendapat mandat untuk mengutip jasa navigasi penerbangan sipil (Route Air Navigation Servises atau RANS fee) atas nama pemerintah Indonesia, untuk selanjutnya diserahkan kepada Pemerintah Indonesia. Untuk wilayah di sektor B dan C tidak dikenai Rans Charge karena masih membutuhkan pembahasan lebih lanjut dengan berbagai pihak. ${ }^{11}$

Indonesia memiliki wilayah udara yang sangat luas, namun teknologi yang dimiliki saat itu masih sangat terbatas. ${ }^{12}$ Belum banyaknya pengalaman dalam mengatur penerbangan, baik komersial maupun militer, mengakibatkan pengelolaan wilayah udara Indonesia, khususnya di Kepulauan Riau dan Natuna, dikelola oleh Singapura berdasarkan mandat dari organisasi penerbangan sipil internasional melalui Regional Air Navigation I (RAN I). ${ }^{13}$ Singapura berinisiatif untuk mengelola pengawasan wilayah udara yang ada di perairan Natuna dan Riau dengan harapan agar wilayah tersebut steril dari pelanggaran udara dan tidak lagi menjadi ancaman.

Inisiatif ini disetujui oleh pemerintah Indonesia dengan pertimbangan bahwa saat itu perairan Natuna dan Riau masih merupakan perairan internasional sehingga insiatif tersebut tidak akan menganggu kedaulatan Indonesia. Perairan tersebut juga dikuasai oleh FIR Singapura dengan ketentuan bahwa di atas ketinggian 20.000 kaki dikelola oleh Singapura, sedangkan di bawah 20.000 kaki

\footnotetext{
${ }^{11}$ Irma Hanafi, FIR (Flight Information Region) di Wilayah Udara Indonesia, disampaikan dalam forum ilmiah di Fakultas Hukum Universitas Patimura pada 28 April 2015.

${ }^{12}$ Awal diserahkannya kontrol FIR Indonesia kepada Singapura yaitu pada saat pertemuan ICAO, Maret tahun 1946 di Dublin, Irlandia

13 RAN merupakan singkatan dari Regional Air Navigation, suatu pertemuan internasional yang membahas tentang navigasi udara di kawasan. RAN I bertempat di Honolulu 1946
} 
dikelola oleh Malaysia. ${ }^{14}$ Penguasaan FIR oleh Singapura berlangsung sejak 1946. Singapura hingga saat ini memegang penuh navigasi penerbangan di daerah Kepulauan Riau dan Natuna, sehingga pelayanan navigasi penerbangan di Kepulauan Riau dan Natuna harus seizin Singapura. Semua Penerbangan yang melewati FIR Singapura yang berada dikawasan Kepulauan Riau dan Natuna harus mendapatkan ATC Clerance dari pengatur lalu lintas penerbangan Singapura. ${ }^{15}$

Pada 1982, Konvensi Hukum Laut Internasional yang mengatur tentang laut, yaitu United Nation Convention on the Law of the Sea, disepakati. Pasca disetujuinya Konvensi Hukum Laut 1982, perairan Natuna dan Kepulauan Riau yang awalnya merupakan perairan Internasional berubah menjadi perairan milik Indonesia. Dalam RAN II di Singapura pada 1983, Indonesia mencoba untuk mengubah hasil keputusan RAN I dan meminta agar Singapura mengembalikan kekuasaan udara di wilayah perairan Natuna dan Kepulauan Riau kepada Indonesia. Namun, usulan tersebut ditolak karena Indonesia dianggap belum mampu untuk mengelola udara di atas perairan tersebut, baik dari segi teknologi, organisasi, hingga sumber daya manusia. ${ }^{16}$

Usaha pengambilalihan FIR oleh pemerintah Indonesia semakin intensif dengan adanya RAN III di Bangkok pada 1993. Indonesia membuat suatu proposal tentang pengembangan pelayanan navigasi penerbangan di atas perairan Natuna dengan membuat Working Paper Number 55 tentang "Kegiatan yang akan direncanakan untuk dilaksanakan di atas Kepulauan Natuna" yang akan meninjau ulang batas FIR. Tujuan utama proposal ini adalah untuk meninjau ulang FIR Singapura yang berada di atas wilayah Indonesia. Pertemuan menyepakati bahwa Working Paper Number 55 dapat diterima, tetapi hal tersebut ditolak Singapura dengan membuat counter paper yang menolak Working Paper tersebut. International Civil Aviation Organization (ICAO) selaku penyelenggara

\footnotetext{
${ }^{14}$ Ramadhita Lestari, "Diplomasi Indonesia Dalam Menyelesaikan Sengketa Fir (Flight Information Region) di Atas Kepulauan Natuna Dengan Singapura” Jom Fisip, Vol. 1, No. 1, 2016, hlm. 5

${ }^{15}$ Irma Hanafi, FIR (Flight Information Region) di Wilayah Udara Indonesia, disampaikan dalam forum ilmiah di Fakultas hukum Universitas Patimura, pada 28 April 2015

${ }^{16}$ Ibid
} 
RAN III menyarankan agar masalah tersebut diselasaikan secara bilateral antara Indonesia dengan Singapura. ${ }^{17}$

Persoalan navigasi udara ini menjadi sangat penting karena bukan saja bersinggungan dengan aspek ekonomi, tetapi, lebih luas lagi, juga menyangkut keamanan dan kenyamanan serta martabat kedaulatan bangsa. Pengambilalihan pengawasan FIR di atas Kepulauan Riau dan Natuna memerlukan dukungan fasilitas dan navigasi penerbangan yang canggih serta sumber daya manusia yang terampil untuk dedikasi dalam pelayanan keselamatan penerbangan. Dalam posisi ini, ICAO selaku organisasi penerbangan sipil internasional memiliki wewenang untuk menetapkan aturan mengenai keselamatan penerbangan tanpa mengesampingkan kedaulatan udara suatu negara. Namun, dalam kasus FIR Kepulauan Riau dan Natuna, kedaulatan Indonesia di ruang udara belum dapat ditegakkan karena masih adanya permasalahan terkait pengelolaan FIR yang menyebabkan pelayananan navigasi penerbangan di atas wilayah Kepulauan Riau dan Natuna sampai saat ini masih berada dalam penguasaan Singapura.

\section{Rumusan Masalah}

Berdasarkan uraian yang telah dijelaskan di atas, yang menjadi rumusan masalah dalam penilitian ini, yaitu: pertama, bagaimana dampak yang timbul dari pengelolaan FIR oleh Singapura atas wilayah udara Kepulauan Riau dan Natuna? Kedua, upaya apa yang telah dilakukan oleh pemerintah Indonesia untuk mengambil alih pengelolaan FIR oleh Singapura atas wilayah udara Kepulauan Riau dan Natuna?

\section{Tujuan Penelitian}

Tujuan penelitian ini yaitu untuk mengkaji secara mendalam dampak yang ditimbulkan dari pengelolaan FIR oleh Singapura di atas wilayah udara Kepulauan Riau dan Natuna serta untuk menganalisis upaya hukum yang telah dilakukan

\footnotetext{
17 Niat untuk mengambil alih kembali FIR diawali argumentasi antara penerbang TNI-AU dengan pengawas lalu lintas udara Singapura. Pada saat itu seorang jenderal ikut dalam penerbangan, Pemandu lalu lintas udara Singapura menanyakan siapa yang ada dalam pesawat udara, dijawab oleh penerbang TNI-AU bahwa di dalamnya ada VIP, tetapi jawaban tersebut tidak memuaskan bagi pemandu lalu lintas udara Singapura, sebaliknya penerbang TNI-AU merasa tidak enak karena terbang di wilayahnya sendiri (Indonesia), tetapi selalu diawasi oleh negara lain.
} 
oleh pemerintah Indonesia untuk mengambil alih pengelolaan Flight Information Region (FIR) Singapura di atas wilayah udara kepulauan Riau dan Natuna.

\section{Metode Penelitian}

Jenis penelitian menggunakan penelitian hukum normatif, yaitu jenis penelitian hukum yang menganalisis suatu permasalahan hukum melalui perjanjian internasional, peraturan perundang-undangan, literatur-literatur, dan bahan-bahan referensi lainnya yang berhubungan dengan pengelolaan Flight Information Region (FIR) di atas kepulauan Riau dan Natuna.

Pendekatan yang digunakan adalah pendekatan perundang-undangan (statute approach), pendekatan ini dilakukan dengan cara menelaah semua peraturan perundang-undangan yang terkait dengan isu hukum yang diteliti. Tujuan pendekataan ini digunakan adalah untuk menemukan konsistensi dan kesesuaian antara satu undang-undang dengan undang-undang lainnya, undangundang dengan regulasi lainnya, serta undang-undang dengan undang-undang dasar. Selain pendekatan perundang-undangan, pendekatan kasus (case approach) juga digunakan dengan melakukan telaah pada kasus-kasus yang berkaitan dengan permasalahan hukum yang dibahas. Kasus yang ditelaah adalah kasus yang telah memiliki kekuatan hukum tetap. Peneliti perlu memahami ratio decidendi atau alasan-alasan hukum yang digunakan hakim sehingga sampai pada sebuah putusan dalam menangani sebuah kasus. Jadi, dalam pendekatan kasus ini, rujukan yang digunakan bukanlah diktum putusan pengadilan, tetapi alasan hukumnya. Alasan hukum inilah yang dijadikan argumentasi dalam memecahkan masalah hukum yang dibahas.

Penelitian ini menggunakan bahan hukum primer seperti Paris Convention 1919, Chicago Convention on International Civil Aviation 1944, United Nation Convention on the Law of the Sea 1982, Agreement between the Government of the Republic of Indonesia and the Government of The Republic of Singapore on the Realigment of the Boundary between the Singapore Flight Information Region and the Jakarta Information Region, Keputusan Presiden Nomor 7 Tahun 1996, ${ }^{18}$ Peraturan Pemerintah Nomor

18 Tentang Pengesahan Agreement Between The Government Of The Republic Of Indonesia And The Government Of The Republic Of Singapore On The Realignment Of The Boundary Between The Singapore Flight Information Region And The Jakarta Flight Information Region 
3 Tahun 2001 tentang Keamanan dan Keselamatan Penerbangan, Perjanjian Kerjasama antara Kementerian Luar Negeri Republik Indonesia, Tentara Nasional Indonesia dan Kementerian Perhubungan Republik Indonesia Tentang Izin terbang (Flight Clearance) Pesawat Udara Asing Tidak Berjadwal Nomor 4 Tahun 2011, dan Undang-Undang Nomor 1 Tahun 2009 tentang Penerbangan (UndangUndang Penerbangan).

Prosedur pengumpulan bahan hukum dalam penelitian ini dilakukan melalui studi pustaka yang diawali dengan melakukan inventarisasi bahan hukum serta klasifikasi bahan hukum yang tersedia untuk digunakan sebagai pedoman dalam menjawab rumusan masalah yang ada.

\section{Hasil Penelitian dan Pembahasan}

\section{Implikasi yang Ditimbulkan dari Pengelolaan FIR oleh Singapura di atas Wilayah Udara Kepulauan Riau dan Natuna}

Perjanjian tentang pengalihan batas FIR Singapura dan FIR Indonesia (Agreement between the Government of the Republic of Indonesia and the Government of The Republic of Singapore on the Realigment of the Boundary between the Singapore Flight Information Region and the Jakarta Information Region) ditandatangani di Singapura pada 21 September 1995. ${ }^{19}$ Beberapa hal pokok yang terdapat dalam perjanjian yang ditandatangani pada tahun 1995 dan diperkuat melalui Keputusan Presiden Nomor 7 Tahun 1996 tentang Pengesahan Agreement between the Government Of the Republic of Singapore on the Realignment $f$ the Boundary between the Singapore Flight Information Region and the Jakarta Flight Information (Keppres No.7/1996) adalah:20

a. Indonesia mendelegasikan tanggung jawab pemberian pelayanan navigasi penerbangan di wilayah sektor A kepada Singapura dari permukaan laut sampai ketinggian 37.000 feet.

19 Menurut Peraturan Direktur Jenderal Perhubungan Udara Nomor: KP 235 Tahun 2014 tentang Pedoman dan Standar, Flight Information Region (FIR) adalah suatu ruang udara dengan batas-batas tertentu yang telah ditentukan, dimana pelayanan informasi penerbangan dan pelayanan siaga (alert) diberikan. Tujuan pembagian FIR adalah untuk menjamin keamanan dan keselamatan penerbangan yang ditetapkan oleh Negaranegara yang tergabung dalam International Civil Aviation Organization (ICAO). Indonesia sendiri telah menjadi negara anggota ICAO sejak April 1950 dan telah diratifikasi dalam Undang-Undang Nomor 15 Tahun 1992 dengan Undang-Undang Nomor 1 Tahun 2009 yang mengacu pada Konvensi Chicago 1944. (Lihat Muhammad Fitrah Zulkarnain, Flight Information Region (Fir) Singapura dan Dampaknya Terbadap Kedaulatan dan Keamanan Indonesia, Departemen Ilmu Hubungan Internasional Fakultas Ilmu Sosial Dan Ilmu Politik Universitas Hasanuddin, 2018, hlm. 3)

20 Amrizal Mansur, "Flight Information Region: Impilikasi Penguasaan Air Traffic Control oleh Singapura di Kepulauan Riau”, Jurnal Universitas Pertahanan Indonesia, hlm. 63 
b. Indonesia mendelegasikan tanggung jawab pemberian pelayanan navigasi penerbangan wilayah sektor B kepada Singapura dari pemukaan laut sampai dengan ketinggian tak terhingga (unlimited height).

c. Sektor C tidak termasuk di dalam perjanjian.

d. Atas nama Indonesia, Singapura memungut jasa pelayanan navigasi penerbangan atau Rans Charges di wilayah udara yuridiksi Indonesia pada Sektor A, selanjutnya diserahkan ke pemerintah Indonesia, sedangkan Sektor B dan C tanpa Rans Charges karena masih merupakan permasalahan Indonesia dan pemerintah Malaysia.

Mencermati Keppres No. 7/1996 di atas, dampak dari keberadaan FIR Singapura dalam pelaksanaanya telah banyak menimbulkan kendala, baik dari segi penerbangan sipil Indonesia maupun pelaksanaan operasi penegakan hukum di wilayah sekitar Tanjung Pinang dan Natuna, baik yang dilaksanakan oleh Komando Pertahanan Udara Nasional (Kohadunas) melalui satuan yang berada di bawah jajaranya, yakni Komando Sektor I (KOSEK I) maupun Angkatan Laut Tentara Nasional Indonesia yang melaksanakan operasi maritim karena pengendalian ruang udara tersebut ada pada Air Traffic Cintrol Singapura (ATC Singapura). ${ }^{21}$ Harus dipahami di sini bahwa wilayah udara Indonesia masuk dalam FIR Singapura. Pendelegasian ini tidak termasuk pendelegasian terhadap kedaulatan negara. Hal ini didasarkan atas Pasal 1 Konvensi Chicago 1944, yang mengatur "The high contracting State recognize that over power has complete and exclusive over the airspace above its territory". ${ }^{22}$

Dengan demikian, ruang udara di wilayah suatu negara tetap merupakan wilayah kedaulatan udara pada negara tersebut dan bukan sebagai wilayah bebas untuk dilalui oleh penerbangan internasional. Oleh karena itu, kewenangan penegakan hukum atas wilayah Indonesia yang masuk dalam FIR Singapura, apabila terjadi pelanggaran kedaulatan, tetap mengikuti jurisdiksi negara Indonesia. ${ }^{23}$

Hal ini merupakan upaya pengawasan dan pengamanan terhadap semua pesawat udara asing dan merupakan langkah antisipatif terhadap ancaman

${ }^{21}$ Chappy Hakim, Quo V adis Kedaulatan Udara Indonesia, Red \& White, Jakarta, 2012, hlm. 189

22 Pasal 1 Konvensi Chicago 1944

${ }^{23}$ Persetujuan terbang adalah suatu bentuk Izin tertulis yang dikeluarkan oleh Kementerian Perhubungan Republik Indonesia bagi pesawat udara sipil asing tidak berjadwal untuk melintas/dan atau mendarat di wilayah Negara Kesatuan Republik Indonesia dalam kurun waktu tertentu dalam rangka melakukan pengawasan dan pengendalian kapasitas angkutan udara dan/atau hak angkut (traffic right) dan/atau penggunan pesawat udara 
pelanggaran wilayah udara. Ruang udara nasional mempunyai sifat yang tertutup, mengingat ruang udara yang merupakan media gerak sangat penting bagi pesawat terbang, terutama dari sudut pandang pertahanan dan keamanan negara yang berada di bawahnya.

Selain permasalahan di atas, dampak lainnya adalah terkait dengan kontrol terhadap ruang udara nasional yang dikuasai oleh FIR Singapura yang sering digunakan untuk latihan militer pesawat tempur Singapura. Walaupun Perjanjian Kerjasama Pertahanan (Defense Cooperation Agreement/DCA) antara Indonesia dengan Singapura sudah dihentikan sepihak oleh Indonesia pada 200, tetapi Satuan Radar 213 Tanjung Pinang dan Satuan Radar 212 Natuna sering menangkap pergerakan pesawat asing, khususnya pesawat militer Singapura yang melakukan black flight di wilayah yang dikenal dengan Military Training Area 1 (MTA 1) dan Military Training Area 2 (MTA 2). Tentu saja, landasan keselamatan memegang peranan penting dalam melandasi penentuan FIR. Namun, landasan kedaulatan juga sama pentingnya dikarenakan terkait dengan pertahanan Indonesia. ${ }^{24}$ MTA 1 membentang dari barat daya Singapura hingga Tanjung Pinang dan utara Pulau Bintan, Kepulauan Riau. Sementara, MTA 2 membentang mulai dari timur Singapura sampai kepulauan Natuna. ${ }^{25}$

Masa berlaku MTA I dan MTA 2 telah berakhir dan Pemerintah Indonesia telah memutuskan untuk tidak memerpanjang Perjanjian antara Indonesia dan Singapura tentang Agreement between the Government of the Republic of Indonesia and the Government of the Republic Singapore on Military Training Area 1 dan 2 (MTA) yang ditandatangani pada 21 September 1995 dan berakhir pada 2001. Enam tahun kemudian, tepatnya April 2007, Singapura dan Indonesia kembali membuat kesepakatan yang diberi nama Perjanjian Kerja Sama Pertahanan atau Defense Cooperation Agreement (DCA). DCA mengatur lebih banyak hal dibanding MTA. Sampai saat ini, DCA belum diratifikasi oleh Indonesia.

24 Asep Adang Supriyadi, Masita Dwi Mandini Manessa, mRudy Agus Gemilang Gultom, “:Isu Penyelarasan Flight Information Region di Atas Wilayah Natuna Issue on Flight Information Region above Natuna Area", Jurnal Manajemen Transportasi \& Logistik, Vol. 05 No. 03, November 2018. Hlm. 261

${ }^{25} \mathrm{CNN}$ Indonesia Sengkarut Area Militer Singapura di Langit Indonesia m.cnnindonesia.com/nasional/20151004172628-20-82700/sengkarut-area-militer-singapura-di-langit-indonesia/ diakses pada tanggal 12 April 2017 
Civil Authority Singapura menetapkan Danger Area pada MTA 1 dan MTA 2 serta daerah FIR yang berada di atas territori Indonesia sebagai area latihan militer yang membuat daerah tersebut menjadi zona terlarang (prohibited area) secara sepihak tanpa persetujuan dengan Indonesia. Berdasarkan Penjelasan Pasal 7 ayat (1) Undang-Undang Penerbangan, adalah kewenangan dari setiap negara berdaulat untuk mengatur penggunaan wilayah udaranya dalam rangka keselamatan masyarakat, keselamatan penerbangan, perekonomian nasional, lingkungan hidup, serta pertahanan dan keamanan nasional. Kawasan udara terlarang (prohibited area) adalah kawasan udara dengan pembatasan yang bersifat permanen dan menyeluruh bagi semua pesawat udara. Pembatasan hanya dapat ditetapkan di dalam wilayah udara Indonesia.

Beberapa negara mengakui bahwa seluruh pesawat militer yang melaksanakan penerbangan di ruang udara internasional yang dikendalikan suatu FIR harus mematuhi prosedur yang telah ditentukan dalam FIR. Dengan adanya pengaturan terhadap suatu wilayah udara oleh negara lain, pesawat militer yang melaksanakan kegiatan penerbangan harus melaporkan ke badan pelayanan lalu lintas udara negara yang mengelolanya. Jika kondisi ini dikaitkan dengan strategi militer, maka hal demikian akan menjadi sangat merugikan karena seharusnya pergerakan militer itu mengandung unsur kesiapsiagaan, kerahasiaan, dan pendadakan. 26

Berdasarkan Pasal 5 Perjanjian Penataan FIR Singapura, ditentukan bahwa apabila Pemerintah Indonesia bermaksud melaksanakan kegiatan, misalnya operasi pertolongan dan latihan militer, yang akan memengaruhi para pengguna ruang udara yang telah didelegasikan ke Singapura, maka Direktorat Jenderal Perhubungan Udara Indonesia akan memberitahukan kepada Badan Penerbangan Sipil Singapura tentang kegiatan tersebut, sesuai dengan ketentuan ICAO. Selanjutnya, Badan Penerbangan Sipil Singapura akan memberitahukan kepada seluruh penerbangan sipil internasional mengenai kegiatan tersebut sesuai dengan ketentuan ICAO.

${ }^{26}$ Harry Purwanto, " Rute Penerbangan di atas Alur Kepulauan Perspektif Indonesia", Perspektif Hukum, Vol 14, No. 1, 2014, hlm. 15 
Atas dasar itu, pemerintah Indonesia dengan demikian tidak mempunyai kedaulatan yang utuh dan penuh atas ruang udara tersebut. Indonesia menjadi tidak bebas untuk menggunakan ruang udara bagi kepentingan militernya. Kedaulatan Indonesia atas ruang udaranya yang utuh dan penuh, dikaitkan dengan ruang udara yang telah didelegasikan pengendalianya kepada Singapura, telah dibatasi dengan ketentuan Pasal 5 perjanjian tersebut.

Selain hal-hal di atas, karakteristik keunggulan kekuatan udara, seperti kecepatan, penyusupan, dan pendadakan seringkali dijadikan sebagai teori dasar untuk menghancurkan center of gravity musuh, sehingga dalam pertempuran udara, strategi penggunaan kekuatan udara akan selalu terkait dengan pencapaian keunggulan di udara. Karakteristik kekuatan udara berupa resiko penguasaan ATC adalah sangat besar karena ancaman yang dihadapi ada di depan mata. ${ }^{27} \mathrm{Hal}$ ini semakin bertambah karena berbatasan dengan negara tetangga yang mempunyai kemampuan militer yang cukup baik, sehingga FIR yang saat ini masih dikontrol oleh Singapura berpengaruh terhadap pertahanan dan keamanan di ruang udara Indonesia.

Upaya yang telah Dilakukan oleh Pemerintah Indonesia untuk Mengambil Alih Pengelolaan Flight Information Region (FIR) Singapura di atas Wilayah Udara Kepulauan Riau dan Natuna.

Beberapa upaya pemerintah Indonesia untuk mengembalikan wilayah udara di atas kepulauan Natuna dan Kepulauan Riau telah tercatat sejak 1983, meskipun terkadang upaya tersebut menemui kendala atau bahkan ditolak karena Indonesia dianggap belum mampu untuk mengelola udara di atas perairan tersebut, baik dari segi teknologi, organisasi, hingga sumber daya manusia. Adapun upaya yang telah ditempuh oleh pemerintah Indonesia, di antaranya:

Pertama, membentuk Perusahaan Umum Lembaga Penyelenggara Pelayanan Navigasi Penerbangan (LPPNPI) berdasarkan Peraturan Pemerintah Nomor 77 Tahun 2012 tentang Perusahaan Umum (Perum) Lembaga Penyelenggaraan Pelayanan Navigasi Penerbangan Indonesia. Tujuan didirikannya LPPNPI ini adalah untuk menyediakan pelayanan navigasi penerbangan dengan baik di

27 Amrizal Mansur, Op. Cit., hlm. 64 
seluruh Indonesia, karena pada awalnya pelayanan navigasi penerbangan di Indonesia ini dilakukan oleh beberapa instansi. Misalnya, UPT Ditjen Perhubungan, PT. Angkasa Pura I, PT. Angkasa Pura II, dan bandar udara khusus, sehingga menyebabkan adanya perbedaan tingkat kualitas pelayanan navigasi dan tidak fokusnya penyelenggara pelayanan navigasi penerbangan. Selama ini, di Indonesia sendiri, ada 2 ruang udara yang masing-masing di kelola oleh PT. Angkasa Pura 1, yaitu Makassar Air Traffic Service Center (MATSC), dan PT. Angkasa Pura 2, yaitu Jakarta Air Traffic Service Center (JATSC), yang masing-masing standarnya berbeda. Jadi, diharapkan, pelayanan akan memiliki standar yang sama dan bisa lebih baik dengan adanya manajemen melalui LPPNPI. ${ }^{28}$

Kedua, Indonesia juga telah mengupayakan untuk masuk dalam Dewan Penerbangan Sipil Internasional (ICAO) pada 2016. Bila Indonesia ingin mengajukan realignment FIR, upaya Indonesia dalam Pengambilalihan Pelayanan Navigasi Penerbangan pada Tingkat ICAO berdasarkan regulasi Air Navigation Plan dalam pengesahan sidang regional Planning and Implementation Regional Group membutuhkan persetujuan terlebih dahulu dari negara-negara anggota ICAO lainnya, karena negara lain juga yang akan menggunakan pelayanan navigasi. Maka dari itu, Indonesia dan Singapura sempat mengajukan proposal joint latter kepada ICAO agar dibahas di dalam sidang. Namun, pada akhirnya, proposal tersebut belum dapat menerima persetujuan dari ICAO karena adanya keberatan yang disampaikan oleh pihak Malaysia, di mana, bila Indonesia mampu mengelola wilayah yang didelegasikan sebelumnya kepada Singapura, yaitu sektor A, B, C, hal demikian dianggap tidak menguntungkan Malaysia, terutama pada sektor $B$ karena adanya hak akses penerbangan dari Malaysia Barat ke Malaysia Timur dan sebaliknya.

Keberatan Malaysia tersebut didasari dengan adanya perjanjian antara Indonesia dan Malaysia tentang "Rejim Hukum Negara Nusantara dan Hak-hak Malaysia di Laut Teritorial dan Perairan Nusantara serta Ruang Udara di atas Laut Teritorial Perairan Nusantara dan Wilayah Republik Indonesia yang terletak di antara Malaysia Timur dan Malaysia Barat", yang ditandatangani pada 25 Februari

${ }^{28}$ Bagian Hukum Sekretariat Direktorat Jenderal Perhubungan udara Kemenhub 
1982, serta telah diratifikasi oleh Indonesia melalui Undang-Undang Nomor 1 Tahun 1983 tentang Pengesahan Perjanjian antara Republik Indonesia dan Malaysia tentang Rejim Hukum Negara Nusantara dan Hak-hak Malaysia di Laut Teritorial dan Perairan Nusantara serta Ruang Udara di atas Laut Teritorial, Perairan Nusantara dan Wilayah Republik Indonesia yang Terletak di antara Malaysia Timur dan Malaysia Barat pada 25 Februari 1983.

Ketiga, kerjasama AirNav Indonesia dengan The MITRE Corporation Air Nav Indonesia mempunyai program dalam hal modernisasi alat navigasi penerbangan di Indonesia yang diberi nama Indonesia Modernization of Air Navigation Services (IMANS). ${ }^{29}$ Program ini diluncurkan untuk meningkatkan sistem navigasi penerbangan di Indonesia. Sebagai negara kepulauan, Indonesia memiliki 237 bandara dan ruang udara yang luas. AirNav ingin meningkatkan kualitas layanan navigasi, baik dari segi alat maupun kualitas sumber daya manusia. Atas dasar itu, AirNav Indonesia melakukan kerjasama dengan perusahaan asal Amerika Serikat, yaitu The MITRE Corporation (the MITRE) pada 6 Oktober 2015. The MITRE akan menjadi konsultan Indonesia dalam melakukan moderenisasi pelayanan navigasi di seluruh Indonesia. Kerja sama AirNav dan The MITRE ini meliputi kegiatan di bidang keselamatan dan keamanan penerbangan, moderenisasi sistem navigasi penerbangan, pengembangan dan peningkatan pelayanan dukungan penerbangan dan analisis kapasitas, serta pengembangan dan perencanaan ruang udara dan bandar udara. Kerja sama ini berdurasi selama lima tahun dengan pilihan dapat diperpanjang untuk lima tahun berikutnya dengan nilai kontrak kerjasama sebesar US\$ 2.3 juta. Indonesia melalui kerjasama ini diharapkan dapat memperbaiki pelayanan navigasi penerbangan dan juga menyamai teknologi navigasi penerbangan dengan negara di kawasan Asia Tenggara.

\section{Penutup}

Berdasarkan uraian di atas, dapat ditarik kesimpulan bahwa dampak yang ditimbulkan dari pengelolaan FIR oleh Singapura di atas wilayah udara Kepulauan Riau dan Natuna salah satunya adalah pengaruhnya terhadap pertahanan dan

${ }^{29} \mathrm{http}: / /$ www.airnavindonesia.co.id/id/page/articleDetail/485?title=Percepat+Modernisasi+Pelayanan+ Navigasi+Penerbangan\%2C+AirNav+Indonesia+Gandeng+MITRE diakses 24 Mei 2017 
keamanan di ruang udara Indonesia, di mana, Civil Authority Singapura menetapkan Danger Area pada MTA 1 dan MTA 2 serta daerah Flight Information Region yang berada di atas territori Indonesia sebagai area latihan militer yang menjadikan daerah tersebut menjadi zona terlarang (prohibited area) secara sepihak tanpa persetujuan dengan Indonesia. Dengan adanya larangan tersebut, tentunya pesawat militer Indonesia yang melaksanakan kegiatan penerbangan harus melaporkan ke badan pelayanan lalu lintas udara negara yang mengelolanya, dalam hal ini Singapura. Jika kondisi ini dikaitkan dengan strategi militer, maka akan menjadi sangat merugikan bagi Indonesia karena seharusnya pergerakan militer itu mengandung unsur kesiapsiagaan, kerahasiaan, dan pendadakan.

Adapun di antara upaya yang telah dilakukan oleh pemerintah Indonesia untuk mengambil alih pengelolaan Flight Information Region Singapura di atas wilayah udara kepulauan Riau dan Natuna, yaitu pertama, membentuk Perusahaan Umum Lembaga Penyelenggara Pelayanan Navigasi Penerbangan (LPPNPI) berdasarkan Peraturan Pemerintah Nomor 77 Tahun 2012 tentang Perusahaan Umum (Perum) Lembaga Penyelenggaraan Pelayanan Navigasi Penerbangan Indonesia. Tujuan didirikannya LPPNPI ini adalah untuk menyediakan pelayanan navigasi penerbangan dengan baik di seluruh Indonesia. Kedua, Indonesia telah mengupayakan untuk masuk dalam Dewan Penerbangan Sipil Internasional (ICAO) pada 2016. Upaya Indonesia dalam Pengambilalihan Pelayanan Navigasi Penerbangan pada Tingkat ICAO berdasarkan regulasi Air Navigation Plan dalam pengesahan sidang regional Planning and Implementation Regional Group membutuhkan persetujuan terlebih dahulu dari negara-negara anggota ICAO lainnya. Namun, pada akhirnya, proposal tersebut belum dapat menerima persetujuan dari ICAO karena adanya keberatan yang disampaikan oleh pihak Malaysia. Ketiga, kerjasama AirNav Indonesia dengan The MITRE Corporation. Air Nav Indonesia mempunyai program dalam hal modernisasi alat navigasi penerbangan di Indonesia yang diberi nama Indonesia Modernization of Air Navigation Services. ${ }^{30}$ Program ini diluncurkan untuk meningkatkan sistem navigasi penerbangan di Indonesia.

\footnotetext{
${ }^{30} \mathrm{http}: / /$ www.airnavindonesia.co.id/id/page/articleDetail/485?title=Percepat+Modernisasi +Pelayanan+ Navigasi+Penerbangan\%2C+AirNav+Indonesia+Gandeng+MITRE diakses 24 Mei 2017
} 


\section{Daftar Pustaka}

\section{Buku}

Sakti Hadiwijoyo, Suryo, Perbatasan Negara dalam Dimensi Hukum Internasional, Graha Ilmu, Yogyakarta, 2011.

Isjwara, Fred, Pengantar Ilmu Politik, Binacipta, Bandung, 1996.

Manuputty, Alma, dkk., Hukum Internasional, Rech-ta, Bogor, 2008.

Hakim, Chappy, Quo Vadis Kedaulatan Udara Indonesia, Red \& White, Jakarta, 2012.

Jurnal

Anggraeni, Ni Putu, "Convention on International Civil Aviation", Indonesian Journal of International Law, Vol. 6, No. 4, 2009.

Johan, Eva, "Pengaturan Mengenai Pesawat Udara Militer Menurut Hukum Udara Internasional", Perspektif, Vol. XV, No. 3, 2010.

Lestari, Ramadhita, “Diplomasi Indonesia Dalam Menyelesaikan Sengketa Fir (Flight Information Region) di Atas Kepulauan Natuna Dengan Singapura" Jom Fisip, Vol. 1, No. 1, 2016

Mansur, Amrizal, “Flight Information Region : Impilikasi Penguasaan Air Traffic Control oleh Singapura di Kepulauan Riau" Jurnal Universitas Pertahanan Indonesia.

Purwanto, Harry, " Rute Penerbangan di atas Alur Kepulauan Perspektif Indonesia", Perspektif Hukum, Vol. 14, No. 1, 2014.

Supriyadi, Asep Adang, Manessa, Masita Dwi Mandini, Gultom, Rudy Agus Gemilang, "Isu Penyelarasan Flight Information Region di Atas Wilayah Natuna Issue on Flight Information Region above Natuna Area", Jurnal Manajemen Transportasi \& Logistik - Vol. 05, No. 03, 2018.

\section{Perjanjian Internasional dan Peraturan Perundang-Undangan}

Agreement between the Government of the Republic of Indonesia and the Government of The Republic of Singapore on the Realigment of the Boundary between the Singapore Flight Information Region and the Jakarta Information Region

Chicago Convention on International Civil Aviation 1944

Paris Convention 1919

United Nation Convention on the Law of the Sea 1982

Undang-undang Nomor 17 Tahun 1985 tentang Pengesahan United Nations Convention On The Law of The Sea (Konvensi Perserikatan Bangsa Bangsa Tentang Hukum Laut), Tambahan Lembaran Negara Republik Indonesia Tahun 1985 Nomor 3319

Undang Undang Nomor 1 Tahun 2009 tentang Penerbangan, Tambahan Lembaran Negara Republik Indonesia Tahun 2009 Nomor 4956 
Keputusan Presiden Nomor 7 Tahun 1996 tentang Pengesahan Agreement between the Government of the Republic of Indonesia and the Government of The Republic of Singapore on the Realigment of the Boundary between the Singapore Flight Information Region and the Jakarta Information Region, Tambahan Lembaran Negara Republik Indonesia Tahun 1996 Nomor 7

Peraturan Pemerintah Nomor 3 Tahun 2001 tentang Keamanan dan Keselamatan Penerbangan, Tambahan Lembaran Negara Republik Indonesia Tahun 2001 Nomor 4075

Perjanjian Kerjasama antara Kementerian Luar Negeri Republik Indonesia, Tentara Nasional Indonesia dan Kementerian Perhubungan Republik Indonesia Tentang Izin terbang (Flight Clearance) Pesawat Udara Asing Tidak Berjadwal Nomor 4 Tahun 2011

\section{Internet}

AirNav Indonesia "AirNav Indonesia Inisiasi Pembentukan KP3I", http:/www/airnavindonesia.co.id/id/page/newsDetail/477?tittle=AirN av+Indonesia+Inisiasi+Pembentukan+KP3I diakes pada tanggal 8 Mei 2017

AiNav Indonesia, http://www.airnavindonesia.co.id/id/page/articleDetail/ 485?title=Percepat+Modernisasi+Pelayanan+Navigasi+Penerbangan $\% 2 \mathrm{C}$ +AirNav+Indonesia+Gandeng+MITRE, diakses pada 24 Mei 2017

AirNav Indonesia, http://www.airnavindonesia.co.id/id/page/about/type/ airspace diakses pada 4 Mei 2017

Pramono, Agus, "Kedaulatan wilayah udara: sudahkah kita menegakkanya? (Telaah kasus FIR Kepulauan Riau dan Natuna) eprints.undip.ac.id/46737 diakses pada tanggal 5 Mei 2017

Seminar Nasional Bagian Hukum Internasional Fakultas Hukum Universitas Diponegoro bekerjasama dengan Kementrian Perhubungan RI Pelayanan penerbangan / Flight Information Region (FIR) di ruang udara wilayah negara berdaulat "Kedaulatan wilayah udara: sudahkah kita menegakkanya? (Telaah kasus FIR Kepulauan Riau dan Natuna) eprints.undip.ac.id/46737 diakses pada tanggal diakses pada tanggal 25 April 2017

Purwanto, Harry," Rute Penerbangan di atas Alur Kepulauan Perspektif Indonesia", Perspektif Hukum, http://perpus.hangtuah.ac.id/ojs/index.php/ perspektif/article/view/28/25 diakses pada 25 januari 2017

CNN Indonesia Sengkarut Area Militer Singapura di Langit Indonesia m.cnnindonesia.com/nasional/20151004172628-20-82700/sengkarut-areamiliter-singapura-di- langit-indonesia/ diakses pada tanggal 12 April 2017

Indonesia Aviation Aerospace Watch "Akankah kita biarkan kondisi yang terjadi di ruang tamu" Negara Kesatuan Republik Indonesia (NKRI) yang secara nyata-nyata telah mengancam Sovereignty, Security dan Dignity 
Indonesia?“. http://iaaw.co.id/berita- terbaru/sovereigntysecurity-dandignity-indonesia diakses pada tanggal 26 April 2017

http:// www.airnavindonesia.co.id/id/page/articleDetail/485?title=Percepat+M odernisasi+Pelayanan+Navigasi+Penerbangan $\% 2 \mathrm{C}+$ AirNav+Indonesia+ Gandeng+MITRE diakses 24 Mei 2017

http:/ / www.cnnindonesia.com/nasional/20151004171137n20n82698/luhutnsing apuranmalaysiandukungnrinkendalikanruang-udara diakses pada 11 Maret 2017

Antara news Indonesia calonkan diri jadi anggota icao 2016-2019 http:/ / m.antaranews.com/berita/527894/indonesia-calonkan-jadianggota-dewan-icao-2016-2019 diakses pada 1 Mei 2017 